\title{
Connections Between Valuing and Values: Exploring Experiences and Rethinking Data Generating Methods
}

\author{
Philip Clarkson, Annica Andersson, Alan Bishop, \\ Penelope Kalogeropoulos and Wee Tiong Seah
}

What do teacher colleagues learn when they read our research? Do they wonder what it might be like to teach values that they are not sure of? Do our research colleagues wonder whether role-play could be a set of new data collection methods we could use?

In the first session of this Discussion Group we explored the background to values and valuing research in mathematics education with short presentations leading to discussion among participants. Presentations were headed 'Enacting values' [review of foundational literature (Clarkson, Bishop, \& Seah, 2010)], 'Projects exploring values and valuing' [describing our work and that of participants (Seah, Andersson, Bishop, \& Clarkson, 2016)], and finally 'Methodology challenges' (discussion of affordances and difficulties encountered with present methods). The last part of the session introduced participants to the notion of role-play (Belova, Eilks, \& Feierabend, 2013). We self divided into a small group of 'students' and a second larger group of 'research observers'. At the core of the role-play was to experience what it was like to act out a given valuing role ('students'), or observing players who do so ('research observers'), and ascertaining whether identifiable behaviours are more likely to be associated with specific values. To this end we discussed with the 'students' how they might play out a role that showed they were valuing one of the six values that Bishop (1988) had identified, and with the 'research observers' we discussed what behaviour they might expect to be associated with each of these values (Clarkson, 2015).

\footnotetext{
P. Clarkson $(\bowtie)$

Australian Catholic University, Melbourne, Australia e-mail: Philip.Clarkson@acu.edu.au 
Session 2 started with the role-play. We then explored the experiences of individuals and the groups of the different 'players'. Interestingly most 'research observers' were able to correctly identify the valuing acted out by the 'students'. However in the following group discussion the different nuances associated with the values, the overlap between them, and the difficulty finding the language to express oneself clearly concerning values and valuing all became evident. We also wondered together whether such an approach would be useful for both teachers and research students in coming to understand more deeply what it feels like to experience valuing a given value, and deciphering what behaviours point to particular values. We concluded that this experiencing did bring a sharper understanding of the role that values play in the teaching and learning of mathematics.

\section{References}

Belova, N., Eilks, I., \& Feierabend, T. (2013). The evaluation of role-playing in the context of teaching climate. International Journal of Science and Mathematics Education, 13, S165S190.

Bishop, A. (1988). Mathematical enculturation. Dordrecht, Holland: Kluwer.

Clarkson, P. C. (2015). Discussion group report: Connections between valuing and values: Rethinking data generating methods. PME Newsletter, November/December, pp. 7-10.

Clarkson, P. C., Bishop, A., \& Seah, W. T. (2010). Mathematics education and student values: The cultivation of mathematical wellbeing. In T. Lovat, R. Toomey, \& N. Clement (Eds.), International research handbook on values education and student wellbeing (pp. 111-136). Dordrecht: Springer.

Seah, W. T., Andersson, A., Bishop, A., \& Clarkson, P. (2016). What would the mathematics curriculum look like if values were the focus? For the Learning of Mathematics, 36(1), 14-20.

Open Access Except where otherwise noted, this chapter is licensed under a Creative Commons Attribution 4.0 International License. To view a copy of this license, visit http://creativecommons. org/licenses/by/4.0/.

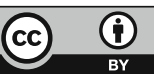

